\title{
One of the Rarest Syndromes in Dentistry: Gardner Syndrome
}

\author{
Guvenc Basaran ${ }^{a}$ \\ Mustafa Erkan ${ }^{b}$
}

\section{ABSTRACT}

Gardner syndrome is a rare, autosomal dominant syndrome. It will follow a positive course with diagnosis and treatment by medical and dental specialists. Orthodontists or general dental physicians can easily diagnose the syndrome through radiological images taken in addition to dental and skeletal findings. The aim of this study was therefore to report two cases of this syndrome and to evaluate it from an orthodontic perspective in order to attract the attention of orthodontists to this rare anomaly. (Eur J Dent 2008;2:208-212)

Key words: Gardner syndrome; Treatment; Diagnose; Radiological evaluation.

\section{INTRODUCTION}

Gardner described a syndrome consisting of hereditary intestinal polyposis with osteomas and multiple cutaneous and subcutaneous lesions in 1953. ${ }^{1}$ This syndrome has since been modified by the addition of other features such as osteomas, supernumerary teeth, dental abnormalities, fibrous dysplasia of the skull, fibromas, desmoid tumours, epidermoid cysts and a number of malignant tumors. ${ }^{2-4}$

a Associate Professor, Dicle University, Faculty of Dentistry, Department of Orthodontics Diyarbakir, TURKEY.

b Associate Professor, GATA Haydarpasa Military Hospital, Clinic of Dentistry, Department of Orthodontics, İstanbul, TURKEY.

- Corresponding author: Guvenc Basaran Dicle University, Faculty of Dentistry, Department of Orthodontics, Diyarbakir, TURKEY Phone: + 90412 2488101/3410

Fax: + 904122488100

E-mail: basarandadicle.edu.tr
The most important feature of the Gardner's syndrome is the association of multiple colonic polyps (familial adenomatous polyposis coli FAP) with sebaceous cysts and jaw osteomas. The significance of this dominantly inherited condition to the dentist is that the colonic polyps usually undergo malignant change by the fourth decade and the extra-intestinal lesions may be apparent before those in the bowel. ${ }^{5}$ Although these are often subclinical oral manifestations could be diagnostical. As such, early detection of multiple jaw osteomas and/or multiple sebaceous cysts (particularly on the scalp) may lead to appropriate further investigation and treatment which might be life saving. As the syndrome is genetically inherited, diagnosis of this condition also has implications for other family members.,

Skeletal abnormalities, the most common of which are osteomas, are an essential component of Gardner syndrome. The benign tumours are 
characterized by slow, continuous growth, ${ }^{4}$ and occur most frequently in the mandible, the outer cortex of the skull and the paranasal sinuses. The angle of the mandible is a particularly diagnostic site. $^{7}$ The osteomas may be either exostoses, often referred to as peripheral osteomas, or endostoses, which are detectable only radiographically. The radiographic appearance of either type is a localized radiopaque lesion with a sharp border. Another type of lesion has been described, which appears as a large and diffuse radiopaque cotton wool-like area in either jaw, and is referred to as a widespread radiopaque lesion. ${ }^{8}$

Dental abnormalities are present in around $30 \%$ of patients with Gardner syndrome, and may include supernumerary teeth, compound odontomas, hypodontia, abnormal tooth morphology and impacted or unerupted teeth. The highest incidence of dental abnormalities is found in patients with multiple osteomas, but dental changes may be determined in the absence of skeletal lesions, and the dental anomalies are not secondary to bony changes. ${ }^{9}$

The principal cutaneous lesions in Gardner syndrome are multiple epidermoid cysts, present in around $50 \%-65 \%$ of patients. The cysts arise prior to puberty and occur primarily on the face, scalp and extremities. ${ }^{10}$

Desmoid tumors may occur in the skin of the anterior abdominal wall or intra-abdominally. Desmoid tumours are slow growing deep fibromatoses that are histologically benign and have no metastatic potential. ${ }^{11}$ Other cutaneous lesions that have been described in Gardner syndrome include fibroma, lipoma, leiomyoma, neurofibroma, basal cell carcinoma and pigmented skin lesions. ${ }^{12}$

Only unique and specific findings are observed in dental and skeletal structures, which can easily be diagnosed by an orthodontist or a general dentist. Therefore, the aim of this report is to present new cases of this syndrome, to evaluate it from an orthodontic perspective, and to bring this rare anomaly to the attention of the orthodontic community.

\section{CASE REPORT}

Case 1

A 21-year-old male patient, one of two siblings, presented to our department with dental deficiencies, chewing and aesthetic concerns and asymmetry that had newly emerged in his face. Anamnesis taken from the patient established that his mother and sister had been diagnosed with Gardner syndrome. Severe asymmetry in the mandible was observed at extraoral examination. At intraoral examination, we determined an Angle Class I molar relationship, and we observed that a large number of permanent tooth eruptions had not been completed in the anterior and posterior regions. No anomaly was observed in any intraoral soft tissue (Figures 1 and 2). At radiological examination, congenital deficiency in the right and left upper central teeth, delayed eruption in the maxillary and mandibular canines and $1^{\text {st }}$ and $2^{\text {nd }}$ premolars and supernumerary teeth were observed. There was an increase in density in the structure of the bony trabecular and smooth-nerve radiological formations in the right condyle region and right and left lower jaw angulus region (Figures 3 and 4).

\section{Case 2}

The 24-year-old female patient of the two siblings presented to our department with a desire for a more regular structure. The patient stated at anamnesis that she had undergone more than 15 general surgical operations. She stated that the left $2^{\text {nd }}$ molar had been extracted surgically. No facial asymmetry was observed at extraoral examination. At intraoral examination an Angle Class I anomaly was determined. Congenital deficiency of the permanent canine tooth in the left lower jaw, and delayed eruption in the $1^{\text {st }}$ canine and $2^{\text {nd }}$ premolars in the upper jaw and in the $1^{\text {st }}$ and $2^{\text {nd }}$ premolars in the lower jaw were observed. Apexification had been completed in the lower jaw teeth. Microdontia was observed in the left upper $2^{\text {nd }}$ molar, and a buried and irregular root morphology in the $3^{\text {rd }}$ molar in the left lower jaw (Figures 5 and 6). Variations in the bone trabecular structure and regular radiopaque lesions in the condylar region were observed. Following medical consultations, both sibling patients commenced treatment with the scheduling of orthodontic, surgical and prosthetic therapy (Figures 7 and 8). 


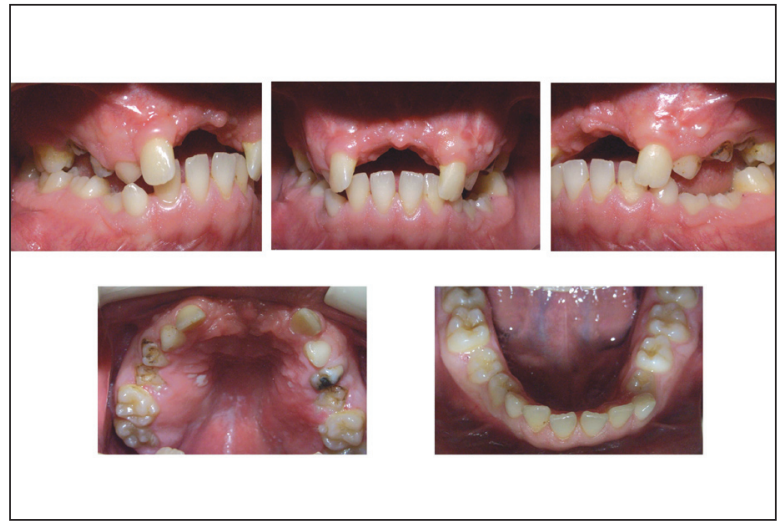

Figure 1. Case 1 intraoral photographs.

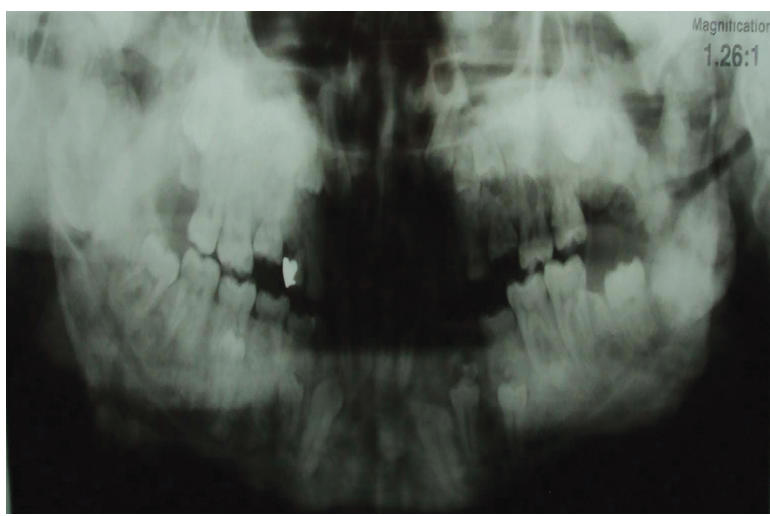

Figure 3. Case 1 panoramic radiography.

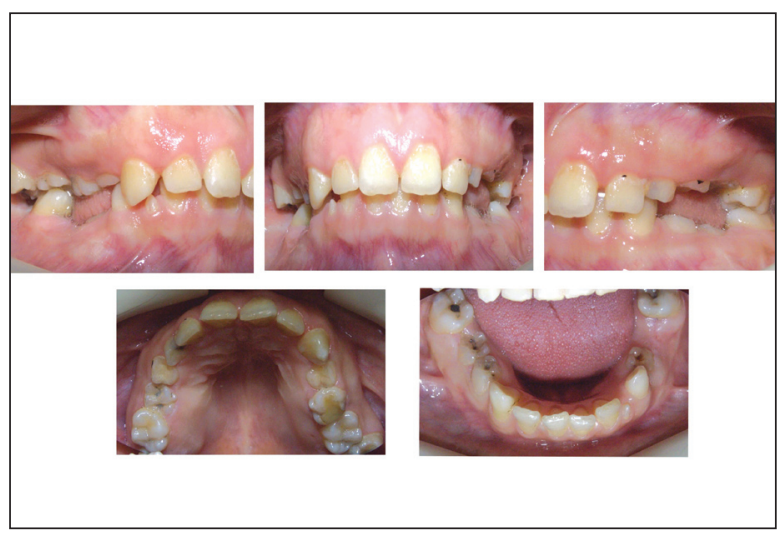

Figure 5. Case 2 intraoral photographs.

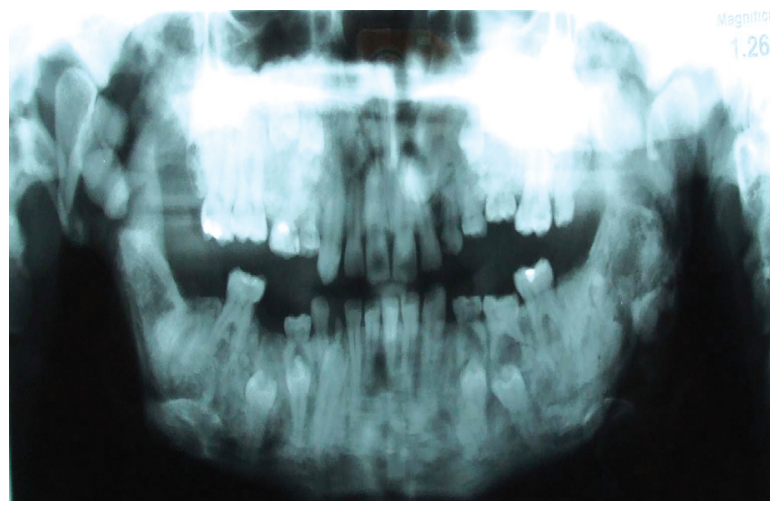

Figure 7. Case 2 panoramic radiography.

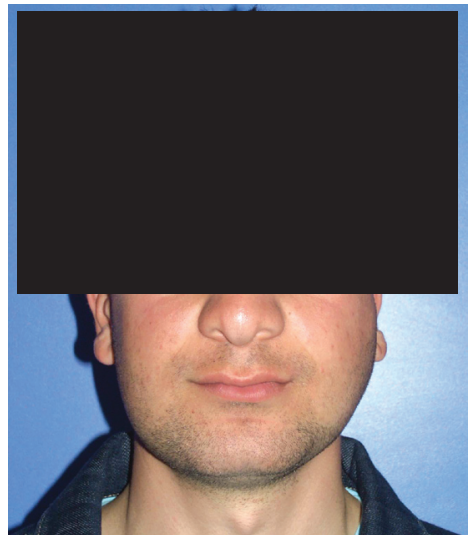

Figure 2. Case 1 extraoral photographs.

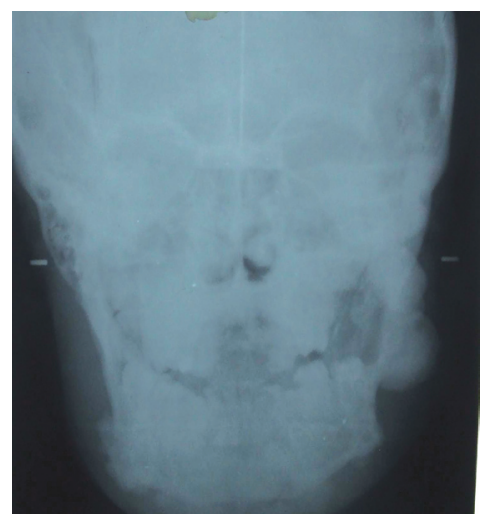

Figure 4. Case 1 antero-posterior radiography.

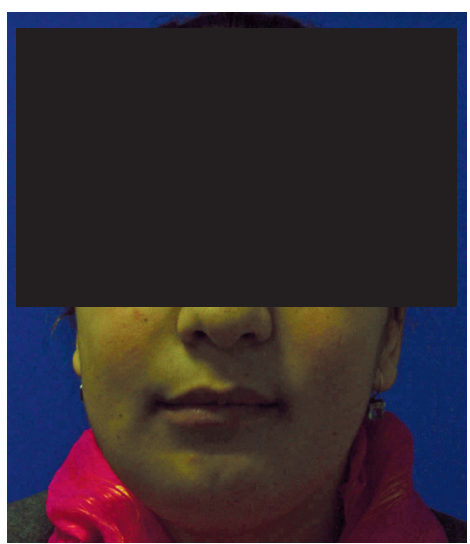

Figure 6. Case 2 extraoral photographs.

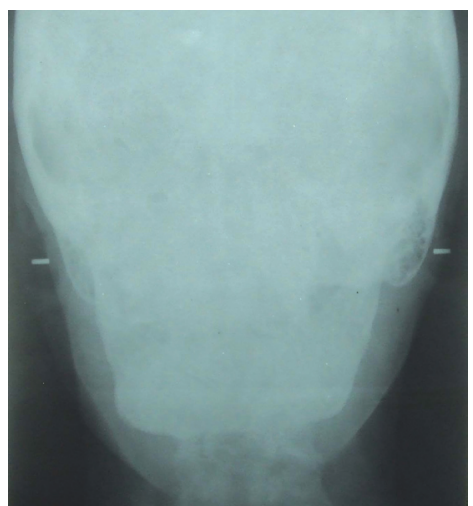

Figure 8. Case 2 antero-posterior radiography.

European Journal of Dentistry 


\section{DISCUSSION}

Gardner syndrome, which has an autosomal dominant character and emerges in relation to the $X$ gene, has an incidence ranging between 1 in 4,000 and 1 in 12,000, depending on region. ${ }^{13}$ It is caused by a dominantly inherited mutation in the adenomatous polyposis coli gene localized on chromosome $5 .{ }^{14}$

Several of these manifestations occur in the oral and maxillofacial region and may be determined during routine dental examination. While a solitary osteoma of the jaw is a common incidental finding in dental panoramic radiography, if more than three such lesions are found this is highly suggestive of Gardner syndrome. ${ }^{14}$ Similarly, dental abnormalities such as supernumerary, absent or unerupted teeth and odontomas are often determined in routine radiography. ${ }^{14}$

In addition to clinical palpation, dental panoramic radiography is very a effective means of detecting the multiple osteomas of the jaws that are a characteristic of Gardner syndrome. ${ }^{15}$ The general dental practitioner may be the first health care professional to suspect such a diagnosis.

Osteomas and odontomas generally emerge in the paranasal sinuses and mandible, particularly in the angulus and corpus regions. ${ }^{16-}$ 18 Pain is rarely observed at these patients and it is asymptomatic. Osteomas and odontomas are generally observed in the post-pubertal period. ${ }^{17}$ Lesions cause facial asymmetry as a result of expansion. They manifest themselves as well defined radio-opacities as a result of routine radiological investigations while inside the medullary bone before cortical expansion. Radiologically, periosteal and endosteal osteomas reveal themselves as well defined nervous sclerotic radiopaque lesions. ${ }^{19-20}$

After diagnosing these osteomas and adontomas, they must be resected under general anesthesia, because of the unreachable regions like paranasal sinuses, condylar and angular region. Also, recurrence of osteomas and odontomas after inadequate surgery could be seen and to eliminate possible occurrence, several surgeries could be performed. Orthodontic treatment is not a valuable option for these patients because osteomas and the increased density of the bone would inhibit tooth movement. The density of the bone is so dense to erupt impacted tooth so surgical extraction would be the most suitable alternative. After extraction of all impacted tooth conventional partial or total prosthetic rehabilitation must be performed.

Histopathological evaluation of resected tissues following surgical intervention, followed by other dental procedures are recommended. Recurrence is rare after surgical intervention. ${ }^{16}$

\section{CONCLUSIONS}

1. Gardner syndrome is a rare condition involving skeletal and dental abnormalities.

2. Although characteristic findings are observed in dental and skeletal structures, which can easily be diagnosed, it is often overlooked by many medical and dental professionals.

\section{REFERENCES}

1. Gardner EJ, Richard RC. Multiple cutaneous and subcutaneous lesions occurring simultaneously with hereditary polyposis and osteomatosis. Am J Hum Genet 1953;5:139-147

2. Antoniades K, Eleftheriades I, Karakasis D. The Gardner sydrome. Int J Oral Maxillofac Surg 1987;16:480-483.

3. Bhama PK, Chugh R, Baker LH, Doherty GM. Gardner's syndrome in a 40-year-old women: successful treatment of locally aggressive desmoid tumor with cytotoxic chemotheraphy. World J Surg Oncology 2006;4:90-100.

4. Takeuchi T, Takenoshita Y, Kubo K, lida M. Natural course of jaw lesions in patients with familiar adenomatosis coli (Gardner's syndrome). Int J Oral Maxillofac Surg 1993;22:226-230.

5. Butler J, Healy C, Toner M, Flint S. Gardner SyndromeReview and report of a case. Oral Oncology Extra 2005;5:8992.

6. Fotiadis C, Tsekouras DK, Antonakis P, Sfiniadakis J, Genetzakis M, Zografos GC. Gardner's syndrome: A case report and review of the literature. World $J$ Gastroenterol 2005; 11:5408-5411.

7. Lew D, Dewitt A, Hicks RJ, Cavalcanti MGP. Osteomas of the condyle associated with Gardner's Syndrome causing limited mandibular movement. J Oral Maxillofac Surg 1999;57:1004-1009.

8. Kubo K, Miyatani H, Takenoshita Y, Abe K, Oka M, lida M, Itoh $\mathrm{H}$. Widespread radiopacity of jaw bones in Familial Adenomatosis Coli. J Cranio Maxillofac Surg 1989;17:350353 
9. Wolf J, Jarvinen HJ, Hietanen J. Gardner's dento-maxillary stigmas in patients with Familial Adenomatosis Coli. $\mathrm{Br} \mathrm{J}$ Oral Maxillofac Surg 1986;24:410-416.

10. Perniciaro C. Gardner's syndrome Dermatol Clin 1995;13:5156.

11. Finan MC, Ray MK. Gastrointestinal polyposis syndromes. Dermatol Clin 1989;7:419.

12. Jones $K$, Korzcac $P$. The diagnostic significance and management of Gardner's syndrome. Br J Oral Maxilofac Surg 1990;28:80-84.

13. Gorlin RJ, Cohen MM, Levin LS. Gardner syndrome in syndromes of the head and neck (3rd ed.) Oxford University Press; 1990: 357-361.

14. Payne M, Anderson JA, Cook J. Gardner's syndrome- a case report. Br Dent J 2002;193:383-384.

15. Rushton VE, Horner K, Worthington HV. Screening panoramic radiology of adults in general practice: radiological findings. Br Dent $J$ 2001;1190:495-501.

16. Bosshardt L, Gordon RC, Westenberg M. Recurrent peripheral osteoma of the mandible: report of case. J Oral Surg 1971;29:446.

17. Kashima K, Rahman OF, Sakoda S. Unusual peripheral osteoma of the mandible - report of 2 cases. $J$ Oral Maxillofac Surg 2000;58:911-913.

18. Longo F, Califano L, Maria G. Solitary osteoma of the mandibulary ramus: report of case. J Oral Maxillofac Surg 2001;59:698-700.

19. Regezi JA, Sciubba J. Oral Pathology $2^{\text {th }}$ edition Philadelphia: WB Saunders Company, 1993:366.

20. Sugiyama M, Suei Y, Takata T, Simos C. Radiopaque mass at the mandibulary ramus. J Oral Maxillofac Surg 2001;59:1211-1214 